\title{
IDENTIFICAÇÃO DE FATORES COMPETITIVOS NO DESENVOLVIMENTO DO PRODUTO ERVA-MATE
}

\author{
ROCHA Jr., W. F. ${ }^{1}$; RINALDI, R. N., ${ }^{2}$ ROCHA, V. L. B.F. ${ }^{3}$.
}

\section{RESUMO}

Este trabalho teve como objetivo o estudo do produto erva-mate para chimarrão tendo como referência teórica o projeto de produto. Para tanto, esta pesquisa utilizou como instrumento de coleta de dados a matriz estrutural prospectiva. Assim, montou-se um sistema que continha quarenta variáveis e construiu-se uma matriz quadrática 40X40 que foi preenchida pelo pesquisador através de entrevistas. De posse das matrizes preenchidas criouse uma matriz com a moda das respostas dos entrevistados, que passou por um processo (desenvolvido por um software de multiplicação matricial que estabilizou e hierarquizou as variáveis do sistema) destacando as mais motrizes (que mais influenciaram o sistema) e as mais dependentes (que mais foram influenciadas); ademais o programa plotou as variáveis num gráfico segmentado em cinco seções. Com base nessa classificação foram selecionadas as variáveis que estavam na seção I (mais motrizes) e seção III ( mais dependentes) do gráfico. De posse dessas variáveis elaborou-se as considerações finais. As variáveis estilo de vida, idade, Portarias 302, Portaria 303, Portaria 519 e Cultura foram as variáveis que mais influenciaram o sistema. Com relação as variáveis mais dependentes figuram as seguintes: embalagem, diferenciação, blend, sabor, que estão envolvidas com o composto de marketing. Assim, as variáveis estudadas podem ser estímulo para um estudo mais aprofundado, objetivando melhorar o desempenho do agronegócio da erva-mate, fornecendo subsídios para o desenvolvimento de estratégias que viabilizem o seu consumo.

\section{PALAVRAS-CHAVES: Erva-mate, projeto do produto, agronegócio.}

\begin{abstract}
The aim of this work was the study of the mate product, using theoretical reference the product project. To reach the objective, this research used as instrument for collection of data the prospective structural matrix. Thus, a system of forty variables was set up and a quadratic matrix 40 X40 was built, and it was filled by the researcher through interviews. A final matrix was created with the mode of the interviews answers. It went by a process (developed by a software which established and order hierarchically the variables of the system. It pointed the variables which more influenced the system and those that received more influence. Moreover, the program plotted the variables on a segmented graphic divided into five parts. Based on this classification the variables were selected into Section I and Section III. Whit

\footnotetext{
${ }^{1}$ Professor Adjunto da Universidade Estadual do Oeste do Paraná (UNIOESTE) - Campus Toledo - Rua da Faculdade, 645, CEP 85903-000. Toledo - Paraná - wrocha@unioeste.br. Pesquisador do do grupo GEPEC.

${ }^{2}$ Professora Assistente da Universidade Estadual do Oeste do Paraná (UNIOESTE) - Campus Toledo. Rua da Faculdade, 645, CEP 85903-000. Toledo - Paraná - rrubiarinaldi@yahoo.com.br

Aluna do programa de doutorado em Engenharia de Produção da Universidade Federal de São Carlos

${ }^{3}$ Professora Dra. da Universidade de Santa Cruz do Sul (UNISC) - Av. Independência, 2293, Santa Cruz do Sul - Rio Grande do Sul - bodini@unisc.br
} 
this later ones the final results were elaborated. The lifestyle, age, Regulations 302, 303 and 519 , and culture were the variables that more influenced the system. In addition, about the more dependents variables there are the next ones: the package, differentiation, blend, flavor, that are involved with the marketing compound. Then, these two kinds of variables can be the beginning of a deeper research, to improve the mates's agribusiness performance, supplying subsidies for the development of strategies to make possible its consumption.

\section{KEY-WORDS : mate, product project, agribusiness.}

\section{INTRODUÇÃO}

O agronegócio da erva-mate é de grande importância econômica para os estados do sul do Brasil, pela geração de empregos e por ser mais uma fonte de renda para as pequenas e médias propriedades agrícolas.

O chimarrão é um hábito cultural nos estados produtores e apesar de seu consumo ter crescido nos últimos anos, vem se delineando uma grande preocupação entre as lideranças do agronegócio em encontrar formas alternativas de uso para a erva-mate, que podem contribuir ainda mais com esse agronegócio. Mas, tratar tanto o chimarrão, como outros produtos que possam ter um uso alternativo para a erva-mate, esbarra em algumas questões que podem comprometer todo o agronegócio.

Um destes problemas está relacionado com a necessidade de proporcionar aos consumidores um produto de melhor qualidade e com características que aumentem a sua demanda. Uma das maneiras de se conseguir esse efeito reside no estudo do desenvolvimento do produto. Assim, levantar os elementos que possam interferir no desenvolvimento do produto passa a ser o objetivo desse estudo, buscando identificar as variáveis que mais influenciam o sistema e as que são mais influenciadas, visando dessa forma o aprimoramento do agronegócio.

O conhecimento utilizado e adquirido pelas organizações, durante e após o desenvolvimento de seus produtos, é fundamental para o desenvolvimento e melhoramento de novos produtos e pelo incremento do seu capital intelectual. Entretanto, segundo Baxter (1995), as atividades de desenvolvimento de um novo produto não são simples e nem diretas; requerem pesquisa, planejamento, controle meticuloso e, o mais importante, o uso de métodos sistemáticos. Esses requerem uma abordagem interdisciplinar, abrangendo marketing, engenharia de produtos e processos, aplicação do conhecimento sobre estética e estilo dentre outros. Nesse processo, a união entre as ciências sócio-econômicas, tecnologia e arte aplicada, não é tarefa fácil, mas é exigida.

Para Back e Forcellini (2000), o desenvolvimento sistemático de produtos possibilita a racionalização dos recursos disponíveis tanto no setor de desenvolvimento, quanto no de execução do projeto propriamente dito.

As idéias para conceitos de novos produtos ou serviços podem vir de fontes externas à organização, como consumidores e/ou concorrentes, e de fontes internas da organização. Porém, para satisfazer e superar as expectativas dos clientes é imprescindível que as empresas reconfigurem-se constantemente e com muita rapidez, objetivando a criação de valor para os clientes. De acordo com Tucker (1999) o valor é produzido quando as empresa atendem às necessidades de um comprador e este considera justo o preço pedido.

Para a obtenção dessa proposta de valor para o cliente, é essencial utilizar-se de estratégias de marketing, que auxiliam o relacionamento com o cliente, ajudando a descobrir suas expectativas e necessidades, antes mesmo que ele próprio as identifique. 
O marketing está presente em toda a vida do produto, até mesmo antes de sua concepção e depois de efetuada a venda, quando continua a procura por novos clientes, o melhoramento do desempenho do produto e o aprendizado com os resultados (Kotler, 2000).

Mas, para obter conhecimento do mercado, dos clientes e seus hábitos, torna-se necessário criar mecanismos para captação, atualização e controle das informações, a fim de antecipar-se às mudanças. Novas práticas fazem-se necessárias e exigem informações sobre os clientes, como estes se comportam e como reagem aos estímulos das empresas. Essas informações são lançadas no banco de dados, que precisa permitir a consulta das informações da maneira precisa para a empresa e no momento certo, criando valor ao produto e à empresa.

Segundo Hooley e Saunders (1996), o estabelecimento de uma estratégia de marketing começa com uma avaliação da capacidade da empresa, pontos fortes e fracos em relação à concorrência, e das ameaças e oportunidades do ambiente. A partir desta análise é formulada a estratégia central da empresa, identificando-se os objetivos de marketing e o enfoque mais amplo para atingí-los.

Porém, para criar estratégias é preciso decidir qual mercados se deseja atingir, o que leva à segmentação de mercado para se posicionar.

\section{I - Segmentação de mercado}

De acordo com Las Casas (1997), uma das primeiras atitudes a serem tomadas pelo administrador de marketing é determinar qual o mercado-alvo. Dependendo da escolha, existem formas diferentes de abordagem: as empresas que escolherem o mercado de consumidores finais terão de conhecer a estrutura do mercado e os hábitos e motivação de compra dos indivíduos, ao passo que a empresa que optar pelo mercado industrial, precisa conhecer, principalmente, as características de compra e uso do produto nas empresas visadas.

\section{II - Planejamento, implementação e controle}

O crescimento e o aprimoramento da organização só serão possíveis se o planejamento e o controle forem utilizados. Conforme Kotler (2000), o planejamento exige consenso, permite que o progresso em relação às metas seja medido e ações corretivas sejam tomadas se as metas não estiverem sendo alcançadas, portanto, é uma parte intrínseca da administração eficiente. Ele permite assegurar que as atividades de marketing alcancem os objetivos organizacionais em consonância com o planejamento estratégico e com a missão e visão da empresa. O plano de marketing deverá conter as estratégias a serem utilizadas, que, segundo Mattar (1998, p.7), "são os caminhos mais adequados, ou cursos de ação determinados para serem seguidos, visando o alcance dos objetivos de marketing no médio e longo prazo [...] Das estratégias definem-se as táticas de marketing, que são as ações ou métodos utilizados para implantar as estratégias de marketing e visam ao atingimento das metas de marketing no curto prazo".

Ao processo de planejamento sucede-se a implementação. Hooley e Saunders (1996), afirmam que neste nível é preciso criar uma organização de marketing capaz de colocar a estratégia em prática, e ainda, que a implementação implica no estabelecimento de um mix de produtos, preços, promoção e distribuição que levam tanto ao posicionamento, como à definição dos próprios produtos e serviços para os mercados-alvo.

Para conseguir oferecer valor constantemente obtendo sucesso através das práticas de marketing, as empresas devem ser permanentemente monitoradas. Sem o monitoramento dos resultados não é possível descobrir qual é o valor que a empresa está gerando, se os seus esforços deram resultados, positivos ou não. Já o controle, segundo Churchill \& Peter (2000), é o processo de avaliar o desempenho em relação a objetivos, planos e estratégias e realizar mudanças quando e onde necessárias.

O planejamento, a implantação e o controle são as etapas que demonstram quais são as 
necessidades com relação à capacitação interna da empresa, necessidades estas que devem ser sanadas a fim de alcançarem-se os objetivos estabelecidos.

Uma vez levantadas todas as informações, segmentado o mercado, realizado o planejamento e capacitação, deve-se definir então o mix de marketing da empresa, ou seja, qual será a oferta de valor ao cliente; é mister definir as estratégias de marketing e detalhá-las, o que implica em definir exatamente que procedimentos devem ser seguidos, ou seja, definir os 4 P's (preço, produto, praça e promoção) da empresa e coordená-los para obter impacto positivo máximo, que significa determinar a relação custo-benefício de diferentes ferramentas e formular o mix que mais favoreça os lucros.(Kotler, 2000)

Satisfazer os clientes e mantê-los comprando é desafio para qualquer pessoa interessada em construir uma empresa bem-sucedida. É necessário se concentrar em construir a fidelidade dos clientes agregando valor aos produtos, oferecendo extras que fazem os produtos se diferenciarem de outros produtos.

Além disso, se espera que com as estratégias de marketing as empresas consigam resolver/minimizar problemas nas erva-mateiras, tais como: falta de planejamento, falta de controle, falta de visão de longo prazo, e principalmente, falta de conhecimento do mercado.

Acredita-se que as empresas possam formar uma base sólida para a sua manutenção e seu desenvolvimento, determinando quais benefícios podem ser conseguidos, quais as condições necessárias e as limitações à efetivação das estratégias.

\section{MATERIAIS E MÉTODOS}

\section{Análise Estrutural Prospectiva}

A análise estrutural prospectiva (AEP) é um ferramental desenvolvido após a II Guerra Mundial e aprimorado na França, servindo como um instrumento de reflexão e delineamento estratégico, tanto para o governo quanto para a iniciativa privada, auxiliando as organizações e os profissionais a traçarem cenários, antecipando e corrigindo possíveis falhas de projetos.

Basicamente, a AEP procura encontrar relações entre as variáveis existentes num sistema, de modo a confrontá-las e a identificar as estruturas existentes entre elas e a sua dependência. Essas estruturas de relação entre as variáveis permitem classificá-las de acordo com a sua motricidade (indicador quantitativo que informa o número de vezes que a variável atua no sistema) e dependência (informa o número de vezes que a variável é influenciada por outras variáveis no sistema)(Gonod, 1986).

No estudo da erva-mate para chimarrão é possível levantar as variáveis do produto através de uma matriz de cruzamentos das variáveis por um processo matemático de multiplicação de matrizes.

É importante, quando se trabalha com a análise estrutural, envolver um grande número de variáveis e, posteriormente, evidenciar as variáveis mais importantes do sistema; proporcionando uma reflexão coletiva sobre o problema estudado possibilitando o trabalho de situações com um grande grau de complexidade.

Sua utilização pode se adequar perfeitamente à compreensão de como se comportam os agentes econômicos do agronegócio da erva-mate na elaboração do produto erva-mate para chimarrão.

Para maior detalhamento da AEP consultar Bodini (2001), que descreve em detalhes as indicações das relações entre as variáveis na matriz, as representações genéricas das influências diretas e indiretas e o princípio do método MICMAC, bem como o estudo das relações diretas e indiretas entre as variáveis.

Levantamento das variáveis: de acordo com Gonod (1986), existem três etapas ao longo do processo de execução do método da AEP: (1) levantamento de todas as variáveis possíveis 
que interferem no sistema; (2) identificação das relações existentes entre as variáveis; e (3) seleção das variáveis mais relevantes.

A primeira etapa consiste em levantar todas as variáveis que envolvem o produto ervamate para chimarrão. Nesse sentido, foi feito, pelos pesquisadores, um levantamento prévio das variáveis utilizando a técnica de brainstorming, listando o maior número de variáveis, sem fazer valor de juízo para nenhuma delas, para evitar a exclusão de alguma variável importante.

A fase seguinte foi a da apresentação das variáveis levantadas para um grupo de especialistas. Esse grupo era formado por pesquisadores e professores com experiência com o produto erva-mate, além de empresários e consultores envolvidos com o agronegócio da ervamate.

Em função do caráter sistêmico do método, foi informado aos profissionais para que selecionassem as variáveis que fossem relacionadas com as demais dentro dos elementos que compõem o produto erva-mate para chimarrão.

O grupo elegeu, por meio de rodadas de discussões, as variáveis mais importantes e relacionadas entre si. Nesse processo houve acréscimo e exclusão de variáveis de acordo com o julgamento e experiência dos especialistas.

É relevante observar que a experiência e o pragmatismo dos profissionais que convivem cotidianamente com o agronegócio da erva-mate foram fundamentais à seleção das variáveis. De acordo com Selltiz et al. (1974), é importante que sejam consultadas pessoas que tenham vasta experiência no campo em que se desenvolve a pesquisa, uma vez que os seus comentários podem colaborar em muito para os estudos desenvolvidos.

O período de levantamento das variáveis, discussão e preenchimento da matriz ocorreu entre os meses de abril a setembro de 2003. No primeiro momento, os pesquisadores elaboraram uma matriz quadrada com aproximadamente 50 variáveis para iniciar o processo de discussão com um grupo maior de pesquisadores e profissionais que atuam no agronegócio da erva-mate. Após, essa matriz foi apresentada a seis pesquisadores que desenvolvem trabalhos com erva-mate e áreas correlatas da Unioeste, Unisc e UFPR para que a matriz fosse analisada no sentido de agregar ou suprimir as variáveis que tinham sido levantadas anteriormente. Assim montou-se uma matriz quadrada com 38 variáveis, que demandou intensas discussões.

Preenchimento da matriz: é a etapa que busca identificar as relações entre as variáveis. Depois de discutida, foi montada a matriz definitiva, a qual foi levada a campo para ser preenchida pelos produtores de erva-mate, industriais e profissionais envolvidos no agronegócio.

Demori (1998) argumenta em seu trabalho que todas as variáveis devem ser muito bem explicitadas, para não causar ambigüidades de interpretação entre as pessoas envolvidas na discussão, já que pode existir uma grande variabilidade de conceitos em função da formação profissional das pessoas, e, então, a definição correta de termos pode poupar esforço, evitando confusão semântica.

A matriz é quadrada, ou seja, possui o número de linhas igual ao número de colunas. Foi preenchida com dois escores: zero (0) e um (1); seja zero (0) quando não ocorre relação nenhuma entre as variáveis confrontadas e um (1) quando há relação entre as variáveis. Tomou-se cuidado para que nenhuma informação ficasse em branco, e também adotou-se a relação da incidência das variáveis coluna sobre as variáveis linha.

Teve-se também o cuidado de definir claramente as variáveis para evitar confusão de conceitos no momento da resposta da matriz. No preenchimento, foi fornecido aos profissionais um catálogo com todas as definições das variáveis, com o objetivo de padronizar os conceitos. Essa matriz foi apresentadas a três empresários da indústria de erva-mate, para que fossem preenchidas.

A terceira etapa foi o preenchimento propriamente dito da matriz pelo pesquisador, na 
qual os respondentes eram indagados e a matriz era preenchida conforme explicação acima mencionada. Embora a matriz ter sido preenchida por valores 0 e 1 o pesquisador sempre observava e indagava aos respondentes vários aspectos do agronegócio da erva-mate que complementavam a matriz.

As matrizes preenchidas foram tabuladas e processadas/analisadas em um programa especialista desenvolvido em linguagem Delphi. Esse programa desenvolve a álgebra das matrizes e encontrou as relações de dependência e motricidade em cada uma das variáveis. Em função da motricidade, o programa hierarquizou em ordem decrescente as variáveis em estudo. Para isso, o conjunto de variáveis necessitava ser estabilizado, ou seja, após uma série de interações matriciais, chegar-se a um ponto em que as variáveis estabilizam a ordenação. Nesse trabalho, na sexta interação, o sistema estabilizou e forneceu a hierarquia em ordem decrescente de motricidade das variáveis.

As variáveis são colocadas em um gráfico dividido em quatro quadrantes, em função da média aritmética resultante da motricidade e da dependência (ver Figura 1).

Segundo Godet (1991), as variáveis podem ser colocadas nesse plano para fornecerem as relações diretas, indiretas e potenciais, de acordo com cada um dos setores onde as variáveis estiverem localizadas. No quadrante I, encontram-se as variáveis motrizes e pouco dependentes (são as variáveis explicativas e que condicionam o sistema). No quadrante II, ficam localizadas as variáveis muito motrizes e dependentes, denominadas variáveis de ligação (qualquer ação sobre essas variáveis repercutirá sobre as demais e também sobre elas mesmas). No quadrante III, estão posicionadas as variáveis que são explicadas pelas variáveis presentes nos quadrantes I e II. O quadrante IV apresenta variáveis pouco dependentes e pouco motrizes, e devem ser desconsideradas do sistema pelas suas poucas ligações com as demais variáveis. Existe, finalmente, uma quinta área (V), em que as variáveis são denominadas variáveis-pelotão. Essa área é delimitada pela variação do desvio-padrão dos valores estabilizados que compõem as motricidades e dependências. Em relação às variáveis contidas nesse setor, a princípio nada se pode dizer. Elas devem receber um tratamento mais detalhado para que alguma inferência seja feita sobre elas.

A última fase ocorre quando as variáveis mais importantes forem destacadas e analisadas. A partir da análise foram feitos os comentários e conclusões finais. É nessa etapa que as variáveis mais motrizes e mais dependentes são selecionadas. O processo de seleção ocorreu segundo os posicionamentos das variáveis no gráfico. As variáveis que se posicionaram nas regiões I e III são as mais importantes e as considerações finais se concentraram nas variáveis presentes nessas duas regiões.

Definição das variáveis: com vista a unificar a avaliação das variáveis pelos diferentes respondentes, foram unificadas as definições conforme a listagem a seguir:

1. Renda: remuneração advinda do trabalho e/ou de aluguel do capital que será utilizado para compra de bens.

2. Cultura: processo ou estado de desenvolvimento social de um povo, uma nação que resulta do aprimoramento de seus valores que irão influenciar na decisão do consumidor.

3. Estilo de vida: modo ou desejo que o indivíduo tem ou busca na vida cotidiana que influencia no comportamento do consumidor.

4. Grupo de referência: determinado grupo (família, amigos, associações, heróis esportivos ou artistas) que influenciam a opinião do consumidor.

5. Informações sobre o processo: conhecimento que o consumidor tem sobre o processo produtivo de fabricação de erva-mate para chimarrão.

6. Fidelidade à marca: relação estabelecida entre o consumidor e uma marca de erva-mate de forma que ele sempre adquire essa marca independente de preço e outras características.

7. Satisfação do consumidor: sensação de bem-estar que o consumidor esboça após comprar 
uma mercadoria.

8. Atendimento ao consumidor: setor da empresa produtora de erva-mate que atende os consumidores para receber críticas e sugestões.

9. Motivação: atitude tomada pelo consumidor espontaneamente ou por outra circunstância que induz a tomar uma decisão de compra.

10. Blend: mistura de tipos de erva-mate que geram um sabor característico ao se tomar o chimarrão.

11. Sabor: sensação gustativa característica as se tomar chimarrão.

12. Cor: coloração que a erva-mate apresenta.

13. Custo: custo ao se produzir erva-mate para chimarrão.

14. Matéria-Prima: folhas de erva-mate que serão secas e trituradas para a confecção de ervamate para chimarrão.

15. Sazonalidade: época que a matéria-prima é colhida (safra e entressafra).

16. Portaria 303: regulamenta, define e qualifica o composto de erva-mate.

17. Portaria 302: regulamenta, define e qualifica a erva-mate para chimarrão.

18. Portaria 519: regulamenta, define e qualifica o chá mate.

19. Portaria 42: trata sobre rotulagem de alimentos embalados.

20. Tipo de embalagem: material usado para o feitio de embalagem para guardar e proteger a erva-mate para chimarrão.

21. Diferenciação do produto: qualquer característica que o produto possui que o torna diferente dos demais pelos mais variados atributos (cor, forma, material ...).

22. Estocagem: armazenamento adequado da erva-mate para chimarrão em todos os locais (inclusive na gôndola do supermercado).

23. Logística: as mais diferentes formas de distribuir a erva-mate para chimarrão.

24. Freqüência: freqüência com que os compradores compram erva-mate.

25. Incerteza: eventos não previstos e não calculados que geram problemas para os agentes.

26. Propaganda: qualquer forma de promover o produto erva-marte para chimarrão.

27. Comunicação Visual: comunicação que a embalagem de chimarrão exerce frente ao consumidor atraindo-o para a compra.

28. Mídia: os mais variados canais de comunicação usados pelas empresas de erva-mate para atingir o consumidor.

29. Preço: preço pago pelo consumidor ao adquirir um pacote de erva-mate para chimarrão.

30. Tecnologia: tecnologia de processo de transformação da matéria-prima em um produto erva-mate para chimarrão.

31. Promoção: as mais variadas técnicas mercadológicas que influenciam na aquisição do produto.

32. Higiene: limpeza necessária para produzir um produto que atenda todas as normas dos órgãos competentes que fiscalizam para o consumo humano.

33. Pesquisa \& Desenvolvimento: investimento feito para o desenvolvimento de produtos com a finalidade de serem adquiridos pelos consumidores.

34. Sazonalidade: período de tempo que geram ciclos de consumo.

35. Público: agentes foco a serem estimulados a adquirir o produto chimarrão.

36. Idade: faixa etária dos consumidores.

37. Sexo: sexo dos consumidores.

38. Hábito Alimentar: tipo de alimentos que o consumidor consome quotidianamente.

39. Embalagem: estrutura que protege, conserva e faz a comunicação do produto.

40. Açúcar: substância que é adicionada ao chimarrão.

41. Diferenciação: maneira de tornar o produto diferente dos demais por custo, forma, ou outro atributo.

42. Propriedade: propriedades alimentares que possui a erva-mate para chimarrão. 
43. Produto Natural: característica que torna o produto isento de produtos agroquímicos.

44. Certificação: processo de acompanhamento para obtenção de credencial de certificação do da empresas e propriedades rurais que atendam as exigências.

45. Procedência: local de onde provém a matéria-prima.

\section{RESULTADOS E DISCUSSÕES}

Após a coleta e o processamento dos dados, foram obtidos os resultados apresentados no Quadro 1, que mostra quais foram as variáveis que mais influenciaram o sistema e quais foram mais influenciadas de maneira direta entre elas.

QUADRO 1- CLASSIFICAÇÃO DAS VARIÁVEIS SEGUNDO A MOTRICIDADE

\begin{tabular}{|c|c|c|c|}
\hline & Variável & $\begin{array}{l}\cdot \bar{J} \\
\stackrel{\Xi}{0} \\
\stackrel{0}{\Sigma}\end{array}$ & 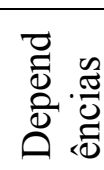 \\
\hline 1 & Portaria 302 & 23 & 4 \\
\hline 2 & Idade & 22 & 2 \\
\hline 3 & Portaria 303 & 22 & 3 \\
\hline 4 & Portaria 519 & 21 & 3 \\
\hline 5 & Propaganda & 21 & 16 \\
\hline 6 & Cultura & 18 & 1 \\
\hline 7 & Estilo de vida & 17 & 5 \\
\hline 8 & Satisfação & 17 & 6 \\
\hline 9 & Renda & 16 & 4 \\
\hline 10 & Hábito alimentar & 16 & 8 \\
\hline 11 & Preço & 15 & 14 \\
\hline 12 & Grupo de referência & 14 & 5 \\
\hline 13 & Sexo & 14 & 2 \\
\hline 14 & Portaria 42 & 14 & 2 \\
\hline 15 & Informação processo & 13 & 1 \\
\hline 16 & Custo & 13 & 12 \\
\hline 17 & Fidelidade & 12 & 7 \\
\hline 18 & Tecnologia & 11 & 12 \\
\hline 19 & Matéria-prima & 9 & 10 \\
\hline
\end{tabular}

\begin{tabular}{|l|l|l|l|}
\hline 20 & Estocagem & 9 & 11 \\
\hline 21 & C. visual & 8 & 16 \\
\hline 22 & Embalagem & 7 & 18 \\
\hline 23 & Sazonalidade & 6 & 1 \\
\hline 24 & A ao consumidor & 5 & 4 \\
\hline 25 & Blend & 5 & 19 \\
\hline 26 & Sabor & 4 & 20 \\
\hline 27 & Mídia & 3 & 14 \\
\hline 28 & Freqüência & 1 & 8 \\
\hline 29 & P\&D & 1 & 16 \\
\hline 30 & Pureza & 1 & 10 \\
\hline 31 & Motivação & 0 & 13 \\
\hline 32 & Higiene & 0 & 14 \\
\hline 33 & Logística & 0 & 7 \\
\hline 34 & Diferenciação & 0 & 16 \\
\hline 35 & Incerteza & 0 & 14 \\
\hline 36 & Propriedades & 0 & 9 \\
\hline 37 & Açúcar & 0 & 15 \\
\hline 38 & Produto natural & 0 & 11 \\
\hline 39 & Certificação & 0 & 5 \\
\hline 40 & Procedência & 0 & 0 \\
\hline
\end{tabular}

Fonte: Dados da Pesquisa

Ao se observar o Quadro 1 percebe-se que as dez variáveis mais motrizes, ou seja, que mais influenciaram o sistema (diretamente), em ordem crescente, foram respectivamente a Portaria 302, idade, Portaria 303 e 519, propaganda, cultura, estilo de vida, satisfação, renda e hábito alimentar. E as dez mais dependentes, ou seja, que mais receberam influência de variáveis do sistema foram: sabor, blend, embalagem, comunicação visual, $\mathrm{P} \& \mathrm{D}$, propaganda, diferenciação do produto, açúcar, higiene e mídia.

É importante ressaltar que questões ligadas à legislação tiveram muita relevância dentro 
do sistema analisado, bem como questões culturais, além da renda. Isso remete a um importante fator muitas vezes negligenciado pelos profissionais que é a instituição (conjunto de normas e regulamentações que moldam e restringem a ação dos agentes). Por outro lado, as variáveis mais dependentes foram as relacionadas ao composto de marketing que tem como expoentes os seguintes elementos: propaganda, comunicação visual, embalagem, mídia, preço, blend, sabor, açúcar. A incerteza também foi uma variável que tem destaque (dependência) nos escores.

Ao se fazer a estabilização do sistema, momento em que as variáveis não mais se alteram na ordem de classificação, observou-se as seguintes alterações: a cultura passa a ser o elemento mais motriz, seguido da portaria 519, portaria 303, propaganda, cultura, estilo de vida, satisfação renda e hábito alimentar, como pode ser observado no Quadro 2.

QUADRO 2 - ESTABILIZAÇÃO DO SISTEMA

\begin{tabular}{|l|l|l|}
\hline Classificação & Ordem crescente de motricidade & Ordem crescente de dependência \\
\hline 1 & Cultura & Sabor \\
\hline 2 & Portaria 519 & Blend \\
\hline 3 & Idade & Diferenciação \\
\hline 4 & Portaria 303 & P\&D \\
\hline 5 & Propaganda & Preço \\
\hline 6 & Estilo de vida & Comunicação visual \\
\hline 7 & Portaria 42 & Custo \\
\hline 8 & Sexo & Açúcar \\
\hline 9 & Hábito alimentar & Propaganda \\
\hline 10 & Grupo de referência & Motivação \\
\hline
\end{tabular}

Fonte: Dados da Pesquisa

Com relação à dependência (Quadro 2), pode-se observar que houve alterações entre as variáveis destacando as variáveis diferenciação e preço. Essa alteração após a estabilização da matriz se deve as relações indiretas que as variáveis do sistema exercem umas sobre as outras. Existem muitas influências indiretas não observadas numa análise mais superficial, após o a multiplicação da matriz essas relações são destacadas proporcionando a alteração na ordem do sistema.

\section{CONCLUSÕES}

Devido à grande quantidade de variáveis fez-se a seleção das mais motrizes e dependentes, utilizando para isso um gráfico que informa qual região abriga as variáveis já estabilizadas (Figura 1). Nesse sentido serão analisadas as áreas da região I e III, que contém respectivamente as variáveis mais motrizes e dependentes.

As variáveis estilo de vida(2), idade(10), Portarias 303 (13), Portaria 302(14), Portaria 519 (15) e Cultura (1) foram as variáveis que mais influenciaram o sistema. As características comuns entre elas residem no grau que cada uma delas restringem a ação dos agentes econômicos nas mais variadas situações e dimensões, de forma que ao desenvolver o produto erva-mate para chimarrão ou outra bebida a base de erva-mate elas devam ser levadas em consideração.

A princípio, falar em atender à legislação vigente pode parecer um tanto trivial, porém é bastante comum encontrar empresas que desenvolvem estratégias para burlar as normas e conseguir no curto prazo levar alguma vantagem financeira sobre a concorrência. Um exemplo que pode ser tomado é a adição de açúcar na erva-mate para chimarrão sem informar 
na embalagem que o produto contém esse ingrediente.

\section{FIGURA 1 - ÁREAS DE MOTRICIDADE E DEPENDÊNCIA IDENTIFICADAS}

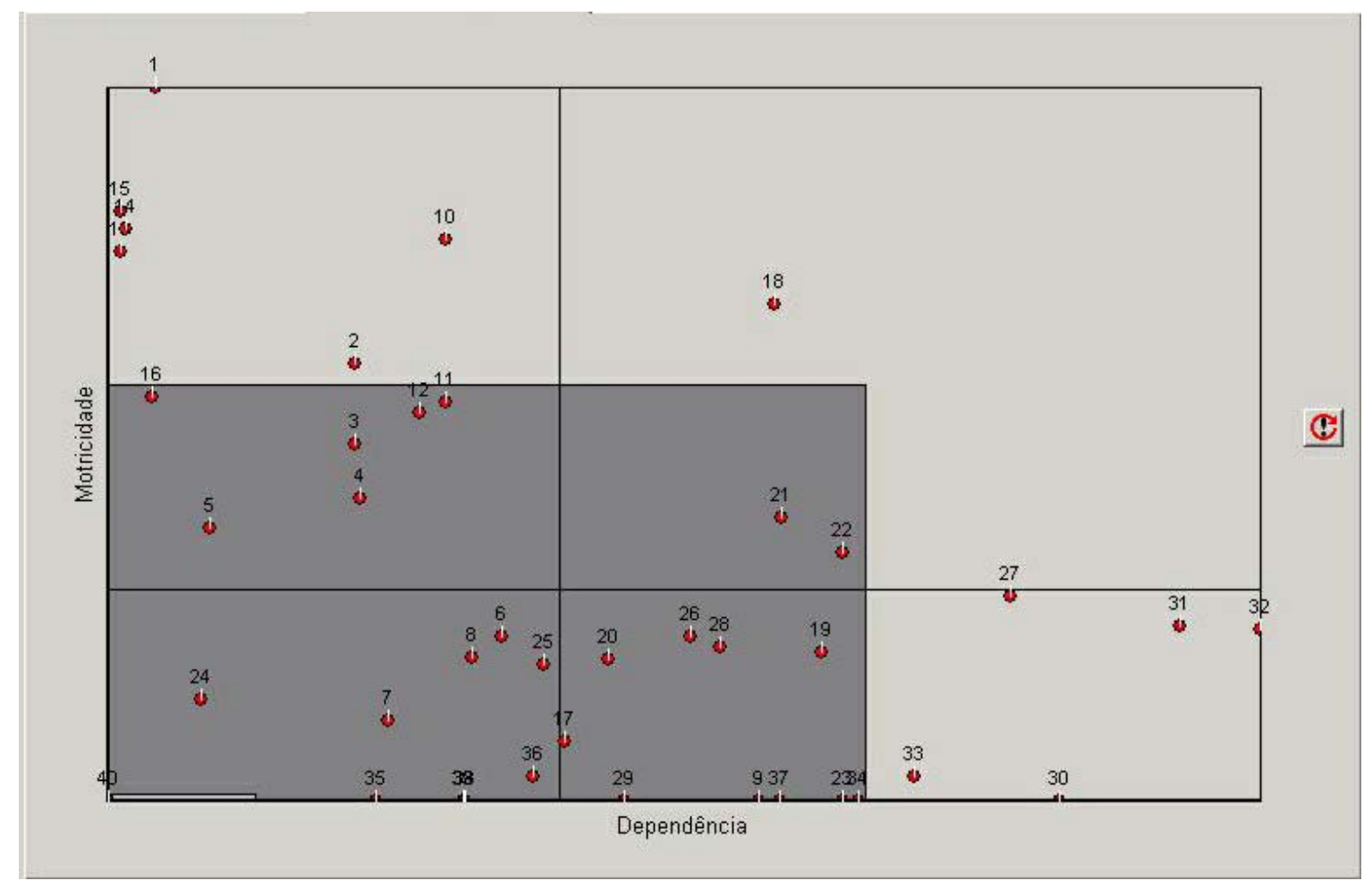

Com relação as variáveis mais dependentes figuram as seguintes: embalagem (27), diferenciação (30), blend (31), sabor (32), que estão envolvidas com o composto de marketing. Isso é um tanto interessante pois essas variáveis vêm corroborar para o entendimento de que o composto marketing deve ser desenvolvido em sintonia com o conjunto de regras e leis que delimitem a ação dos estrategistas de mercado, procurando sempre buscar uma combinação exata entre criatividade e ética. Isso vale também para a variável embalagem que além de comunicar com o consumidor, ter estética, proteger o produto, ela deve informar corretamente o consumidor sobre os componentes que contém o produto.

É importante destacar que a pesquisa e desenvolvimento de produtos foi também um elemento que recebeu muita influência das demais variáveis do sistema mostrando sua importância com estratégia para melhorar o agronegócio.

O processo de diferenciação do produto foi outra variável que recebeu grande influência das demais variáveis do sistema. A diferenciação deve ser uma estratégia que tem um potencial de ser muito bem explorado nos produtos oriundos de erva-mate, quer ser pelo enfoque de preservação do meio ambiente até a especificidade geográfica ou uma marca que fica caracterizada por não usar açúcar, atribuindo características.

Cabe ressaltar ainda que mudanças no segmento industrial são uma tendência marcante em função dos ajustes necessários diante das demandas apresentadas pelos consumidores como relevantes. A concorrência e a competitividade atual são por inovação dos produtos, no sentido de convencer e encantar o consumidor e segmenta-lo ao máximo, personalizando produtos e serviços. Portanto, os investimentos a serem feitos pressupõem inovar com a diferenciação de produtos; criar planos e estratégias de marketing, visando o mercado intensivo; segmentar; inovar e assim por diante.

Assim, as variáveis estudadas podem ser o início de um estudo que pode ser mais 
aprofundado, objetivando melhorar o desempenho do agronegócio da erva-mate, fornecendo subsídios para o desenvolvimento de estratégias que viabilizem o seu consumo.

\section{REFERÊNCIAS BIBLIOGRÁFICAS}

BACK, N.; FORCELLINI, F. Apostila da disciplina de projeto conceitual. Curso de PósGraduação em Engenharia Mecânica, UFSC, Florianópolis, 2000.

BODINI, V. L. Uso da análise estrutural prospectiva para a identificação de fatores condicionantes da competitividade na agroindústria brasileira. 2001. 142f. Tese (doutorado) Engenharia de Produção, Universidade Federal de Santa Catarina, Florianópolis.

BAXTER, M. Product design - A pratical guide to systematic methods of new product development. London: Chapmam \& Hall, 1995.

CHURCHIL JR., G.; PETER, J.P. Marketing - Criando valor para os clientes. São Paulo: Saraiva, 2000.

DEMORI, L. M. Análise de fatores de competitividade do subsetor edificações com o uso do método de matriz de análise estrutural. 1988. 99 f. (Dissertação) - Engenharia de Produção, Universidade Federal de Santa Catarina, Florianópolis.

GODET, M. De l'antecipation à l'action. Paris: Dunod, 1991. 390 p.

GONOD, P. F. Dynamique de la prospective. Etude n. 136, Centre de Prospective et D’Etudes. Grenoble: Aditech, 1989. 159 p.

Cours de prospective: Economie et sociéte. Grenoble: Université des Sciences Sociales de Grenoble, 1986. 243 p.

HOOLEY, G; SAUNDERS,J. Posicionamento competitivo. São Paulo: Makron Books, 1996.

KOTLER, P. Marketing para o século XXI. São Paulo:Futura,2000.

LAS CASAS, P. Marketing: Conceitos, Exercícios e Casos. São Paulo: Atlas, 1997.

MATTAR, F.N. Uma contribuição ao estudo do processo de planejamento empresarial: Uma proposta de modelo para planejamento de marketing. In: http:// www.fauze.com.br/artigo24.htm, 1998.

SELLTIZ, C.; JAHODA, M.; DEUTSCH, M.; COOK, S. Métodos de pesquisa na relações sociais. São Paulo: Editora Pedagógica Universitária, 1974. 687 p.

TUCKER, R.B. Agregando valor ao seu negócio. São Paulo: Makron Books, 1999. 